\title{
OS CONFLITOS AGRÁRIOS FRENTE AS NOVAS DINÂMICAS TERRITORIAIS NO CAMPO MARANHENSE $(1985$ - 2018)
}

\author{
Agrarian conflicts in front of new territorial dynamics in \\ maranhense field (1985 - 2018)
}

\author{
Thiago Ronyerisson Silva Costa \\ Universidade Estadual do Maranhão - UEMA, São Luís \\ ronyrmm@hotmail.com \\ José Sampaio de Mattos Junior \\ Universidade Estadual do Maranhão - UEMA, São Luís \\ sampaio.uema@gmail.com \\ Ronaldo Barros Sodré \\ Universidade Federal do Maranhão - UFMA, São Luís \\ ronaldo-sodr@hotmail.com \\ Igor Breno Barbosa de Sousa \\ Instituto Federal do Norte de Minas Gerais - IFNMG, Diamantina \\ iggor breno@hotmail.com
}

Recebido em 29/11/2020 Aceito em 18/12/2020

RESUMO: O Maranhão, segundo o IBGE (2019), é um estado essencialmente agrário, engloba a maior população rural do Brasil, possui ainda uma ordenação fundiária historicamente concentrada, devido ao processo de incorporação e territorialização concebidos pelo capital, processo facilitado em seu contexto histórico pelo aparato do Estado. Assim, o presente artigo se propõe a analisar o papel do Estado e sua dinâmica de transferência do poder ao capital, como fator determinante para o processo de territorialização, este que se materializa em conflitos e exclusão dos trabalhadores no campo maranhense. A pesquisa foi baseada no método materialismo histórico e dialético com abordagem do tipo quantitativa, foram utilizados em complemento a bibliografia especializada no tema, dados secundários e de softwares de tabulação, auditoria de dados e confecção de mapas. Os resultados obtidos elucidam o elevado índice de conflitos por terra no Maranhão, o qual desencadeiam os processos de conflitos e suas conflitualidades no campo. Portanto, é necessário fomentar a articulação de movimentos dentro da estrutura social para estruturar uma política fundiária efetiva, que pode e deve ser parte de uma estratégia política destinada a combater ao mesmo tempo a desigualdade, a miséria e o desemprego e contribuir para superar o atual modelo de concentração fundiária, aplacar o processo de conflitos e conflitualidades e construir uma sociedade onde a vida tenha mais importância que os interesses do capital.

Palavras-chave: Capital; Conflito; Estado; Território.

ABSTRACT: The Maranhão, according IBGE (2019), is an essentially agrarian state, encompassing the largest rural population in Brazil, and also has a historically concentrated land order, due to the process of incorporation and territorialization conceived by the capital, a process facilitated in its historical context by the state apparatus. Thus, this article proposes to analyze the role of the State and its dynamics of power transfer to capital, as a determining factor for the territorialization process, which materializes in conflicts and exclusion of workers in the Maranhão countryside. The research was based on the historical and dialectical materialism method with a quantitative approach. Specialized bibliography on the subject, secondary data and tabulation software, data auditing and the making of maps were used as a complement. The results obtained elucidate the high rate of land conflicts in 
Maranhão, which trigger the processes of conflicts and their conflicts in the field. Therefore, it is necessary to foster the articulation of movements within the social structure in order to build an effective land policy, which can and should be part of a political strategy aimed at fighting inequality, misery and unemployment at the same time, and contribute to overcoming the current model of land concentration, to placate the process of conflicts and conflicts, and to build a society where life is more important than the interests of capital.

Keywords: Capital; Conflict; State; Territory.

\section{INTRODUÇÃO}

A questão agrária no Maranhão parte da importância de compreender os benefícios que o processo traz para a classe social que a compõe, uma vez que a questão agrária promove o acesso as terras por meio da política da reforma agrária, a qual visa proporcionar qualidade de vida, sustento e renda para as famílias, infraestrutura, entre outros benefícios. Entretanto, o avanço do capital frente as estruturas sociais que ali encontram-se, deu início ao processo de exclusão destas para a instalação de um outro tipo de estrutura, a do capital, mediante a apropriação das terras com o apoio do Estado, principal agente regulador da política fundiária (GERMANI, 2010; OLIVEIRA, 2001).

No cenário nacional, a partir do golpe militar de 1964, intensifica-se a repressão aos movimentos sociais ligados a reforma agrária, por outro lado, o golpe aguça a relação terra capital e a renda fundiária. Com a redemocratização em 1985, efetiva-se a fragilidade de uma reforma agrária politicamente tolerável, mas também o seu limite quanto a futura conjuntura histórica. A partir da promulgação da Constituição de 1988, incorpora-se uma política de compensação, um caminho parcial e tardio para primar o acesso à terra e reparar as históricas injustiças sociais. Analisamos essa nova realidade, tomando como referência o paradigma da questão agrária e o paradigma que envolve o capital ou o capitalismo agrário. Assim, discute-se a perspectiva de execução da política fundiária nos governos Fernando Henrique Cardoso (FHC), Lula e Dilma como estratégia de desenvolvimento territorial ou, em um cenário de regresso político, a implantação de uma política compensatória (COELHO, 2016; FERNANDES, 2005).

No cenário maranhense, o processo de incorporação de terras pelo capital reflete a historicidade do processo nacional e, a partir disso, pode-se compreender as dinâmicas territoriais no campo maranhense. Este, segundo Asselin (2009) inicia-se com a Lei de Terras de 1969, no então governo de José Sarney que concebe um significado bem mais complexo que o escopo de seu objeto estruturante, a terra, pois representa um modelo de apropriação das terras do Estado, o qual configura-se como um novo modelo econômico, sendo a principal representação de uma política pública que instaura ao Estado o papel do principal agente no processo de valorização e expansão da estrutura do capital (empresas, latifundiários, grileiros, entre outros).

Nesse contexto, criam-se órgãos específicos destinados à política fundiária, proposta como política oficial de combate à grave situação social. Porém, com a apropriação de terras pelo capital, iniciam-se as disputas pelo uso desta, pois os conflitos têm seus recursos particulares e a disputa pelo território pode ser um recurso de conflitos 
sociais, políticos, econômicos etc. (SODRÉ; MATTOS JUNIOR, 2016). Ainda assim os conflitos evidenciam também as falhas da estrutura do Estado quanto a correta execução dessa política, assim como mostram a capacidade da estrutura social (pequenos agricultores, assentados, pescadores, quilombolas, indígenas entre outros) e suas organizações, na busca pelos seus direitos apontando o acesso a melhores condições de vida no campo.

Assim, o capital torna-se a principal fonte de incorporação de terras, agente de poder e transformação frente às conflitualidades, estas que segundo Sodré e Mattos Junior (2016), (re) produzem os conflitos por terra e promovem a luta de classes opostas, no qual vence quem melhor utilizar seus mecanismos de poder. Como consequencia, os resultados da luta da estrutura social, contribuem com índices que conduzem o Maranhão a apresentar elevados quadros de desigualdades sociais. Nessa perspectiva, o Maranhão, segundo o IBGE (2019), é o estado que apresenta o maior índice proporcional de pessoas vivendo na pobreza, quase metade da população, que, por sua vez, seja no campo ou nos centros urbanos, encontra-se em péssimas condições de vida, além disso, o IBGE (2010) aponta o Maranhão como estado que concentra a maior população rural do país.

Dessarte, as políticas de uso e acesso à terra, visam dinamizar a reterritorialização da estrutura social frente ao capital. Neste contexto, a política fundiária constitui-se como a principal estratégia para minimizar tais impactos; democratizar o acesso e uso da terra; reduzir os índices de desemprego e pessoal desocupado e, com isso, reduzir o fluxo campo-cidade junto ao processo de macrocefalia urbana; aumentar a produção de alimentos, visto que mais da metade dos alimentos produzidos no país fazem parte da base produtiva da agricultura familiar, que compõe a estrutura social; diversificar as atividade econômicas com participação social; fortalecer a segurança alimentar e refrear os processos de conflitos e suas conflitualidades. Por fim, destaca-se a importância das reformas sociais, não apenas como políticas de compensação, mas como políticas de base para desenvolver o país, sendo a reforma agrária uma política de reterritorialização que compõe uma das ações nessa direção.

Neste sentido, o problema da presente pesquisa é: quais os conflitos agrários no Maranhão frente às novas dinâmicas territoriais, no período de 1985 a 2018? O objetivo que orienta a pesquisa está vinculado a compreensão de analisar o papel do Estado e sua dinâmica de transferência do poder ao capital como determinante para o processo de territorialização, que se materializa em conflitos e na exclusão dos trabalhadores no campo maranhense.

\section{MATERIAIS E MÉTODOS}

Essa pesquisa foi realizada por meio do método Materialismo Histórico e Dialético, este que se caracteriza pela aplicação do estudo da vida social, aos fenômenos da vida da sociedade, ao estudo desta e de sua história. Neste sentido, Marx (2008) afirma que: 
desenvolvera e concentrara na mão do selvagem. O capital, entre outras coisas, é também um instrumento de trabalho, é trabalho passado, objetivado. Logo, o capital é uma relação natural, geral, pois separa precisamente o que é específico e o que do "instrumento de produção", do "trabalho acumulado", se torna capital (MARX, 2008, p. 40).

A abordagem utilizada na pesquisa foi a quantitativa para obter informações que promovessem um retorno ábil ao objetivo proposto. Quanto aos instrumentos utilizados, fez-se uso do software MS Excel 2019 no processo de tabulação, auditoria de dados e confecção de métricas - que visam retratar o cenário de conflitos por terra no Maranhão, suas causas e consequências -, e do QGIS para a confecção de mapas e espacialização dos dados.

Levantamos ainda os dados que compõem este trabalho, junto à Comissão Pastoral da Terra (CPT), Instituto Brasileiro de Geografia e Estatística (IBGE), Instituto Nacional de Colonização e Reforma Agrária (INCRA) e ao mapa de conflitos envolvendo injustiça ambiental e saúde no Brasil (Escola Nacional de Saúde Pública Sérgio Arouca - ENSP/ Fundação Oswaldo Cruz - FIOCRUZ), como parte dos dados secundários que complementam as análises desta pesquisa. Para melhor compreensão do processo metodológico, a figura 1 a seguir expõe o fluxograma de procedimentos adotados na pesquisa.

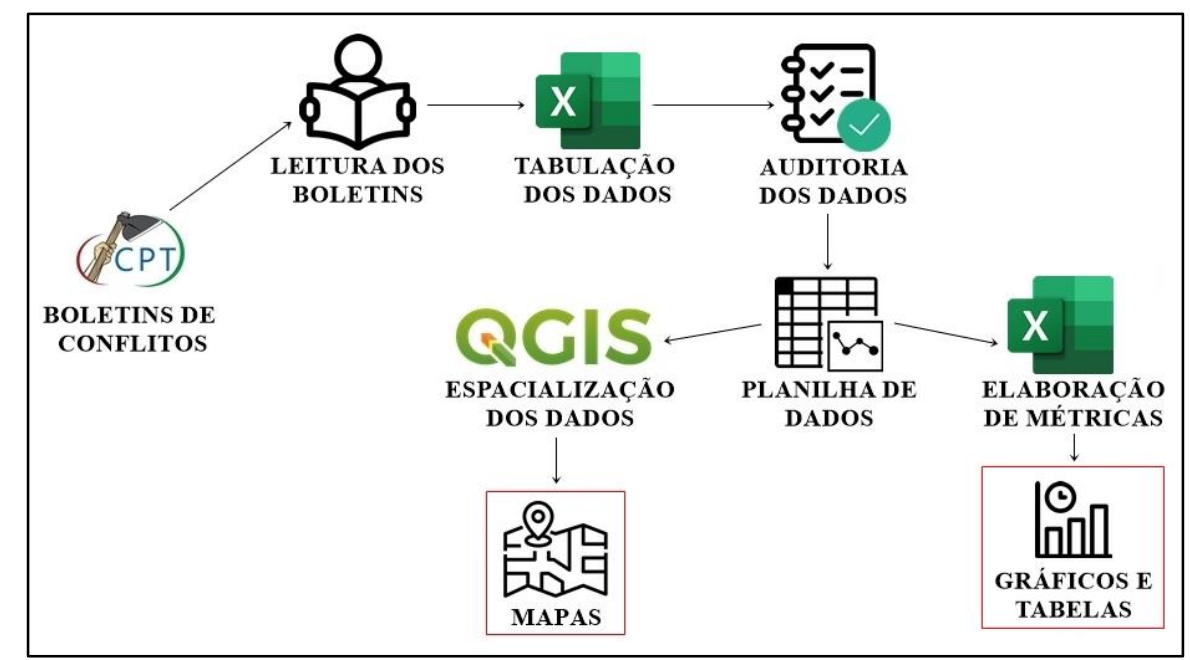

Figura 1. Fluxograma de procedimentos metodológicos de sistematização dos dados.

Elaboração: Os autores.

No procedimento de tabulação, existem dados referente a dois ou mais municípios, visto que alguns conflitos envolvem áreas situadas em territórios de dois ou mais municípios. Diante disso, fez-se a divisão e lançamento dessas informações referentes a cada município e, portanto, os dados por município contabilizam as ocorrências reais em seu território. No procedimento de tabulação dos dados para o estado, as informações são contabilizadas a partir do total geral aferido, excluindo-se o procedimento adotado para os municípios.

Dito isto, busca-se ainda levantar informações sobre conflitos por terra e suas variáveis e, assim, utiliza-se da bibliografia especializada na discussão acerca da 
questão agrária nacional e maranhense, conflitos agrários, território, dos agentes construtores e modificadores do território, bem como da política fundiária.

\section{RESULTADO E DISCUSSÕES}

\section{As ocorrências de conflitos no Maranhão}

O Maranhão ocupa uma área de $333.365,6 \mathrm{~km}^{2}$. Ele expressa, segundo o IBGE (2010), um total de 33.336.560 hectares, dos quais 12.238 .487 hectares ou $36,72 \%$ do total são destinados a atividade da agropecuária. Caracteriza-se como o oitavo e segundo, respectivamente ao Brasil e ao Nordeste em termos de classificação quanto a sua extensão territorial. Embora possua um imenso território, comparável ao da Itália, o Maranhão apresenta um pequeno número de estabelecimentos agropecuários com grandes extensões de terra, que caracteriza o processo de concentração fundiária. Cabe destacar que mais da metade da população do estado concentra-se na zona rural, 2.511 .008 habitantes ou 48,08\% do total, maior percentual em relação a todas as outras unidades da federação (IBGE, 2010).

A concentração fundiária no Maranhão é fruto de um processo histórico que ainda persiste, em que $59,10 \%$ do total de estabelecimentos de até 5 hectares concentram $1,48 \%$ do total de terras destinadas à atividade agropecuária; os estabelecimentos agropecuários com área entre 10 e 9.999 hectares concentram 40,86\% do total de estabelecimentos e $84,51 \%$ das terras.

Nesta perspectiva, Germani (2010) explica que a concentração de terras inicia o processo de conflitualidades territoriais, o qual origina-se em sua maioria pelo avanço do capital como principal agente do processo de territorialização, frente ao contexto histórico e das inúmeras dificuldades encontradas pelos grupos sociais que buscam o processo de reterritorialização como forma de reverter esta permanência histórica. Assim, busca-se identificar a dinâmica dos conflitos por terra no Maranhão como fenômeno que surge a partir da concentração fundiária, expresso na figura 2, a seguir.

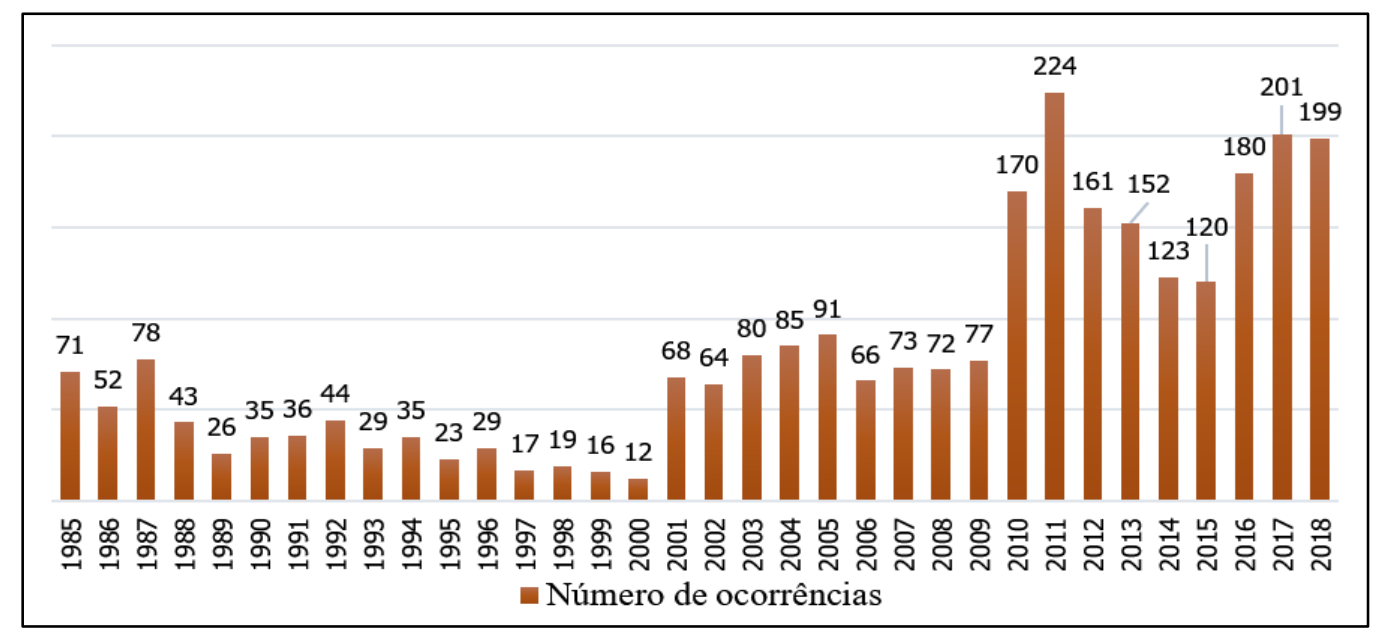

Figura 2. Quantidade de ocorrências de conflitos por terra no Maranhão (1985-2018).

Fonte: CPT, (2019). 
Diante dos dados explicitados, o Maranhão apresenta um total de 2771 conflitos entre os anos de 1985 a 2018 com média de 82 conflitos por terra ao ano. Observa-se ainda, que o período que se inicia em 2001 (anos finais do governo FHC) apresenta um aumento de $82 \%$ no número de conflitos em relação ao ano anterior, a maior variação percentual no período, representando um número maior que a soma dos registros entre os anos de 1997 a 2000. Em seu segundo mandato, FHC desenvolveu uma política agrária extremamente repressora, criminalizando a luta pela terra e desenvolvendo uma política de mercantilização dessa. (FERNANDES, 2003).

O ano de 2010 (final do Governo Lula) apresenta um aumento de 55\% em relação ao ano anterior, em números absolutos apresenta 170 registros e 54 ocorrências a menos que 2011, líder no período. Thomaz Junior (2003), ao analisar o contexto aludido, já advertia para a possibilidade de uma contrarreforma agrária no Brasil nos anos do PT. Os caminhos seguidos pelo governo Lula, em meados de 2003, já indicavam que não haveria mudanças na estrutura fundiária do país, muito menos seria implementada uma reforma agrária que visasse dar autonomia a produção familiar e camponesa.

Em suma, a partir de 2011 a presidente Dilma instituiu o Plano Brasil Sem Miséria, apesar de reconhecer que $47 \%$ do público desse plano vivem no campo, em nenhum momento elege a reforma agrária como caminho para combater o quadro dramático encontrado e reconhecido pelo próprio governo. Segundo Antunes (2015), estruturalmente as diretrizes econômicas do Governo Dilma seguiram basicamente a mesma política do segundo governo Lula, onde um dos pontos foi o incentivo à produção de commodities para a exportação, beneficiando especialmente o capital vinculado ao agronegócio. Isto posto, a figura 3 a seguir, destaca a espacialização dos conflitos por terra no Maranhão entre 1985 e 2015.

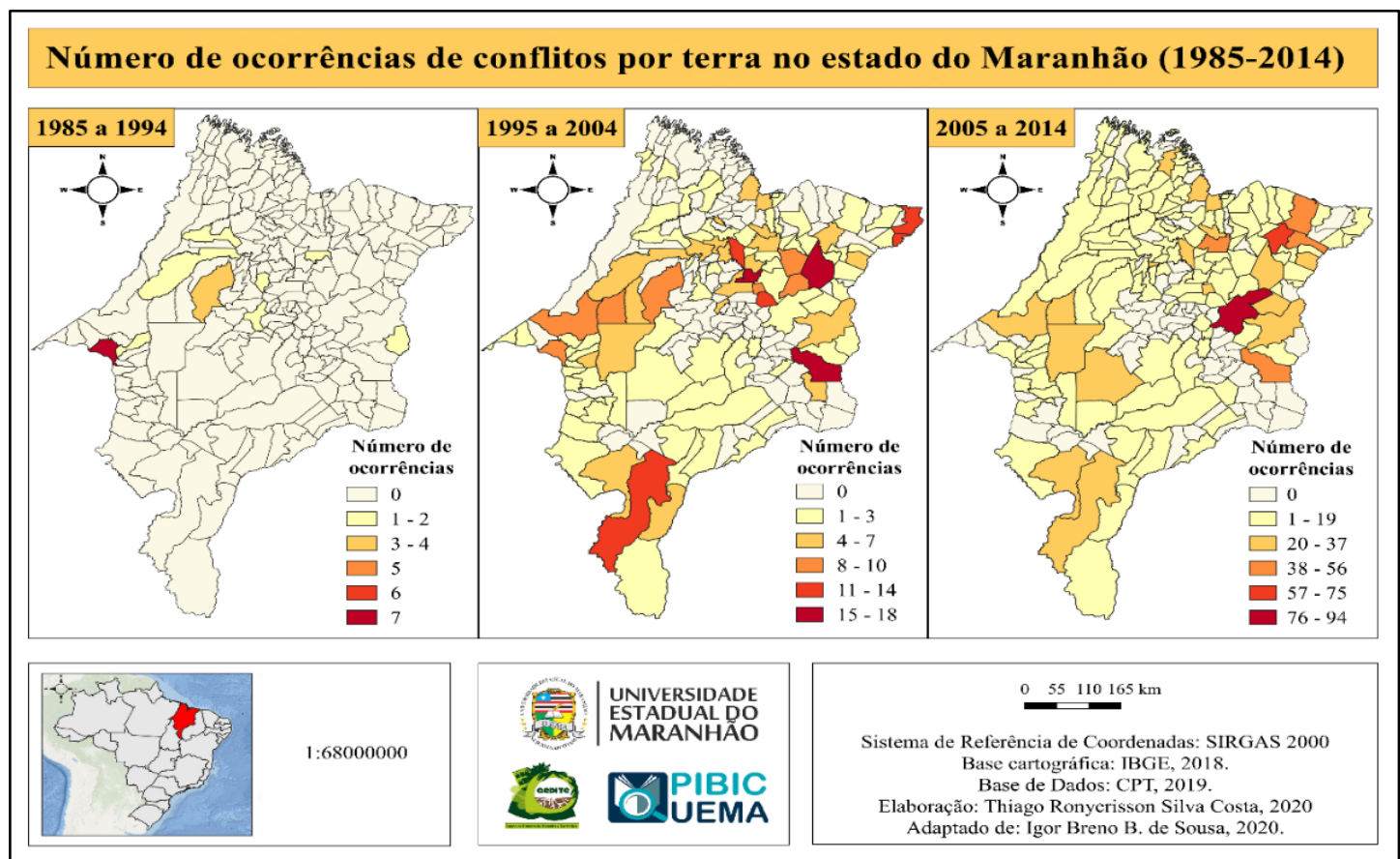

Figura 3. Ocorrências de conflitos por terra no estado do Maranhão (1985 a 2014). Elaboração: Os autores. 
A partir da leitura do mapa, pode-se observar que os casos cobrem grande parte do território maranhense, dos 217 municípios, 161 registraram conflitos por terra para o período analisado, o que significa dizer em termos percentuais que $71,89 \%$ dos municípios tiveram ao menos um conflito por terra nesse mesmo período. Segundo a CPT (1988), na terra do presidente nada foi diferente, segundo estado com o maior número de conflitos na região Nordeste e o quarto a nível nacional. Em complemento:

O Maranhão [...] não está à frente apenas pelos números, a intensidade e o caráter político dos conflitos aqui pesam muito mais, chega-se mesmo a conclusão de que há um terrorismo de Estado [...] tal o envolvimento direto do governo maranhense (CPT, 1985, p. 18).

A partir dos anos de 1990, com a inserção dos projetos desenvolvimentistas, liderados pelo Projeto Grande Carajás, em que pese sua infraestrutura ferroviária e portuária a partir da atuação da mineradora, articulam-se ações para o desenvolvimento de uma forte cadeia produtiva ligada ao carvão vegetal, siderúrgica, álcool e soja (CARNEIRO, 2012 apud ARCANGELI, 1987). Com isso, a expansão das áreas ligadas a extração e cultivo da matéria-prima necessárias para o desenvolvimento dessas atividades, ligadas ao capital e até então ao Estado, atingem a estrutura social ali instalada. $\mathrm{Na}$ mesorregião Oeste do estado, ressalta-se o complexo siderúrgico e sua carência por carvão vegetal, processo que incentiva o avanço do desmatamento, o aumento de carvoarias e o trabalho escravo como consequência da exclusão social e da ausência do direito de acesso à terra.

Nas regiões Leste e Sul maranhenses, observa-se o avanço da monocultura de soja e pecuária a partir de 1995, com destaque para os municípios de Balsas e Chapadinha, estes localizam-se na região conhecida como MATOPIBA, a saber: Maranhão, Tocantins, Piauí e Bahia, região esta conhecida como a última fronteira agrícola do Brasil que concentra uma grande quantidade de latifúndios, apresenta elevados índices de desigualdades sociais e consolida-se como um espaço de exclusão (ALMEIDA; SODRĖ; MATTOS JUNIOR, 2019). Em meio a esse processo, Oliveira (2001) elucida que estamos diante de uma estrutura fundiária violentamente concentrada no Brasil e diante de um desenvolvimento capitalista que reproduz a pobreza.

Desta maneira, o capitalismo no campo brasileiro constitui-se como um sistema ilógico, desigual e combinado, o qual avança submetendo a renda da terra ao capital, ainda assim, Sodré (2017) destaca em meio a esse processo, a intensificação, concentração e o aumento da violência estão ligados à concentração e centralização do poder da classe social vencedora que está alinhada ao capital e se beneficia ausência do Estado. Além do mais, essa territorialização do capital, expropria a estrutura social, aumenta o desemprego, produz riquezas, misérias e conflitualidades (FERNANDES, 2005).

Por fim, o processo que se inicia em meados dos anos de 1980 e 1990 com a chegada da estrutura produtiva liderada pelo capital e facilitada pelo Estado, adentra a segunda década do século XXI, sem passar por grandes alterações no estado do Maranhão. A partir disto, a figura 4 a seguir mostra a espacialização dos conflitos nos últimos quatro anos do período em análise desta pesquisa. 


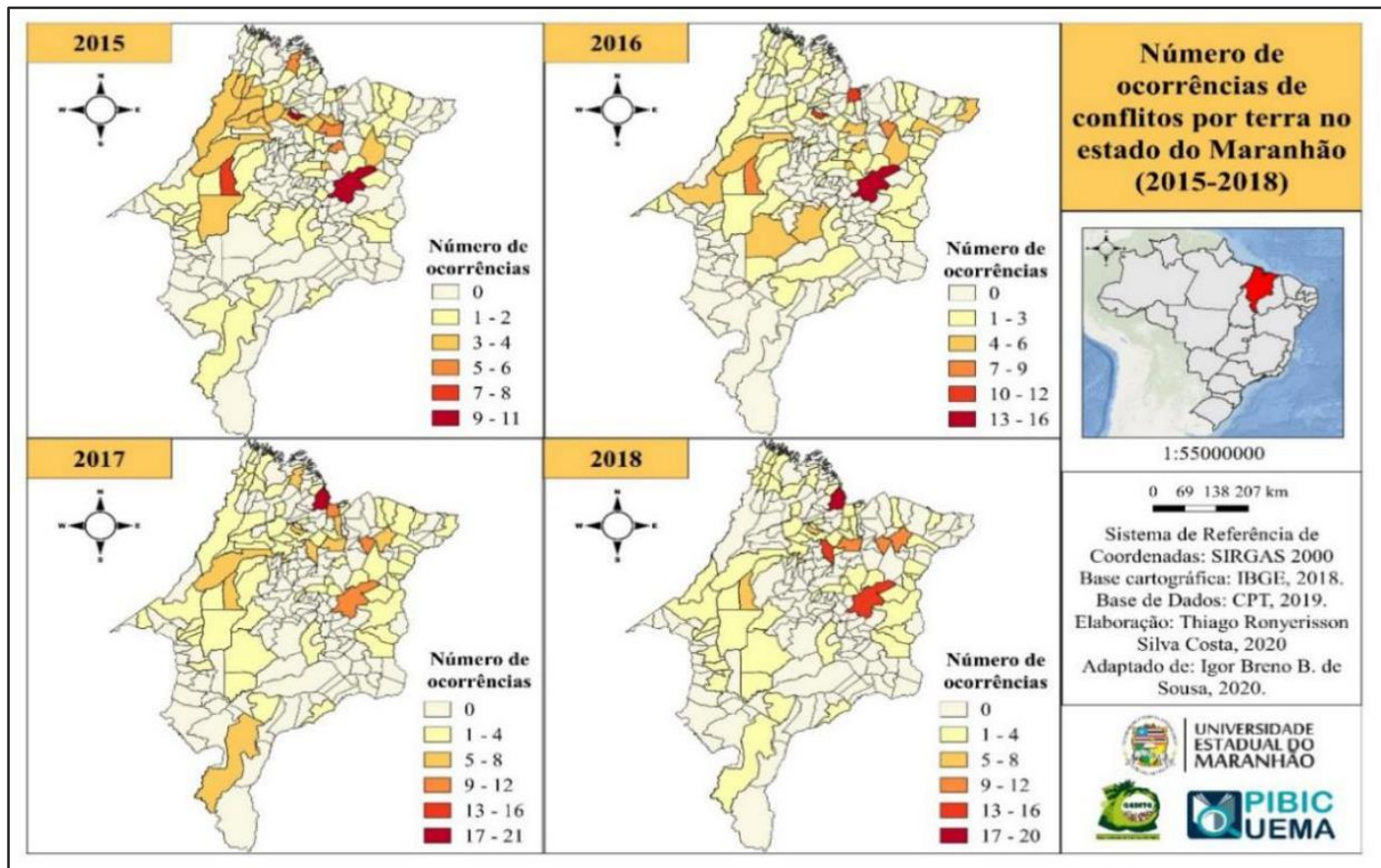

Figura 4. Ocorrências de conflitos por terra no estado do Maranhão (2015 a 2018).

Elaboração: Os autores.

Os anos que compreendem o período entre 2015 e 2018 focalizam o volume de conflitos por terra, estes atingem $74,19 \%$ dos municípios o que engloba 161 municípios maranhenses. Concentram-se principalmente nas regiões que compreendem a cadeia produtiva da monocultura de soja e do avanço da pecuária extensiva na região da Pré-Amazônia Maranhense, com destaque para o aumento no número de conflitos envolvendo indígenas, dado que nesta região encontram-se algumas das principais reservas indígenas do estado.

A CPT (2018) afirma que o Maranhão é o estado que apresenta os maiores registros de conflitos por terra que incluem desde ameaças, assassinatos, prisões, agressões físicas a ações judiciais contra comunidades e lideranças camponesas, indígenas, quilombolas e sindicais. Cenário este que se reflete por toda a Amazônia Legal, área ligada a grandes complexos produtivos atados a estrutura do capital. Salienta-se ainda que a Amazônia Legal é responsável por $96 \%$ da área total em disputa no Brasil, o equivalente a 22.810 .488 hectares.

Ainda de acordo com a CPT (2018), somente em 2018, o Maranhão registrou 199 conflitos por terra, envolvendo 16.154 famílias. Esse número se comparado a 2017, com registro de 201 conflitos por terra e 18.415 famílias envolvidas, identifica-se uma queda no número de famílias afetadas, entretanto, o número de conflitos se manteve igual. Fernandes (2005) colabora ao afirmar que um conflito pode ser "esmagado" ou resolvido, entretanto, o processo de conflitualidade não.

Por fim, o Boletim de Conflitos da CPT (2015) ressalta que no estado do Maranhão, os conflitos por terra, envolvem, sobretudo, as grandes empresas de mineração celulose e os sistemas de monocultura, a qual destaca-se a soja, ambas ligadas a estrutura do capital. 


\section{Áreas de conflitos e famílias envolvidas no Maranhão}

O número de famílias está diretamente ligado ao número de conflitos, a maior participação das famílias está ligada diretamente às ocupações e ao tamanho da área envolvida. Desse modo, o processo de lutas e conflitualidades, as ocupações constituem um momento da luta pela/na terra. Assim, o governo em resposta às ações dos movimentos da estrutura social, criou assentamentos rurais que, segundo Sodré (2017), funcionaram muito mais do que uma situação de regularização fundiária, pois os créditos de fomento, alimentação e de habitação possibilitaram mudanças no quadro social e econômico das famílias.

Entretanto, os assentamentos significam apenas uma etapa da luta pela terra, visto que ainda se faz necessário conquistar condições de vida e produção no campo; resistir na terra e lutar por um outro tipo de desenvolvimento que permita o estabelecimento estável da estrutura social (GIRARDI; FERNANDES, 2008). Além do mais, Fernandes (2005) afirma que o processo de transformação dos espaços em território surge em meio as conflitualidades como destaque para os movimentos sociais e os processos de territorialização. A seguir, a figura 5 traz o panorama a partir da área, em hectares, relacionada a conflitos por terra no estado entre os anos de 1985 a $2018^{1}$.

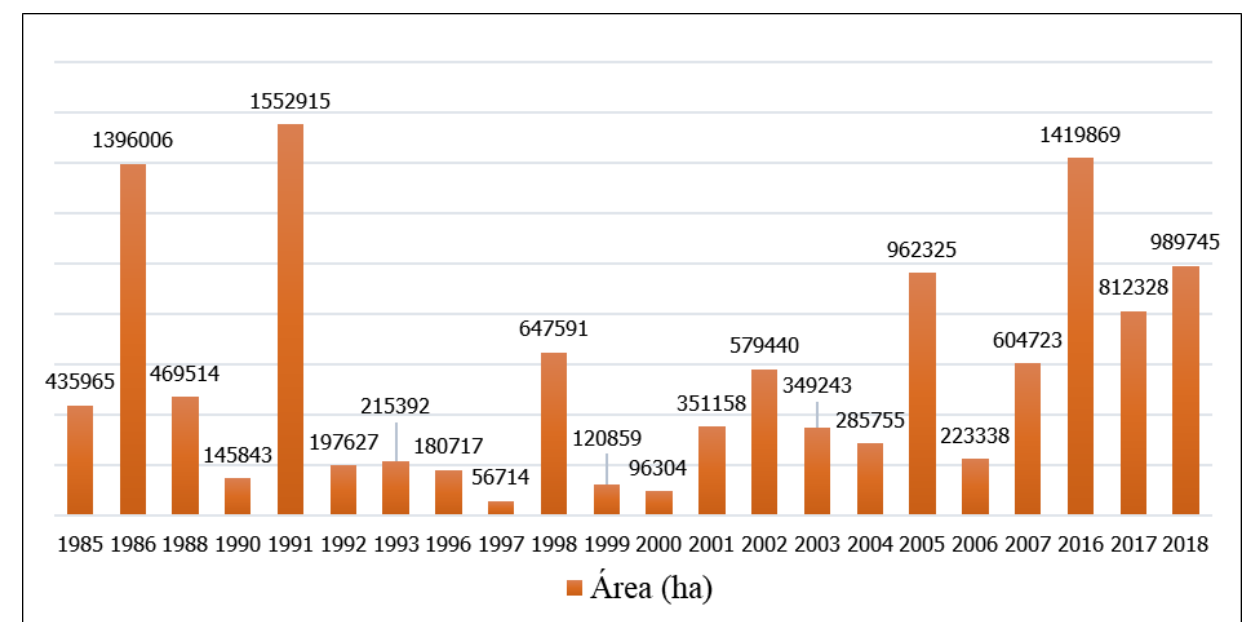

Figura 5. Área relacionada aos conflitos por terra no Maranhão (1985-2018).

Fonte: CPT, (2019).

Nota-se que as áreas relacionadas aos conflitos por terra no Maranhão não mantêm um padrão, apresentam oscilação, ao mesmo tempo que atingem um elevado número. Observa-se que há uma queda acentuada entre os anos de 2002 a 2004, registro de $103 \%$ para este intervalo. Contudo, mantêm-se uma inconstância a partir de então, com anos com índice elevado seguidos de queda. $\mathrm{O}$ ano de 1991 apresenta o maior registro, com 1.552 .915 hectares e 1997 o menor registro, com 56.714 hectares. Ainda assim, somando-se toda as áreas relacionadas a conflitos por terra para o período de

${ }^{1}$ Os boletins dos anos de 1987, 1989, 1994, 1995, 2008, 2009, 2010, 2011, 2012, 2013, 2014 e 2015 não apresentaram dados referente ao número de famílias envolvidas em conflitos por terra.

REVISTA GEONORTE, V.11, N.38, p.243-257, 2020.

DOI: 10.21170/geonorte.2020.V.11.N.38.243.257

(ISSN 2237 - 1419) 
1985 a 2018 , temos o equivalente a $14,87 \%$ do território maranhense diretamente relacionado a conflitos por terra.

Dito isto, Oliveira (2001) denomina o processo de incorporação de terras pela estrutura do capital como o de "monopolização do território" e, a partir desse processo, observa-se a territorialização dos monopólios. Portanto, concentração fundiária a favor da estrutura do capital, em sua maioria terras improdutivas, que, por sua vez, reflete a quantidade de terras relacionadas a conflitos agrários. Neste âmbito, Fernandes (2005) afirma que o processo de transformação dos espaços em território surge em meio as conflitualidades como destaque para os movimentos sociais e os processos de territorialização. A seguir, a figura 6 mostra a espacialização das áreas relacionas a conflitos por terra em território maranhense entre 1985 a 2018.

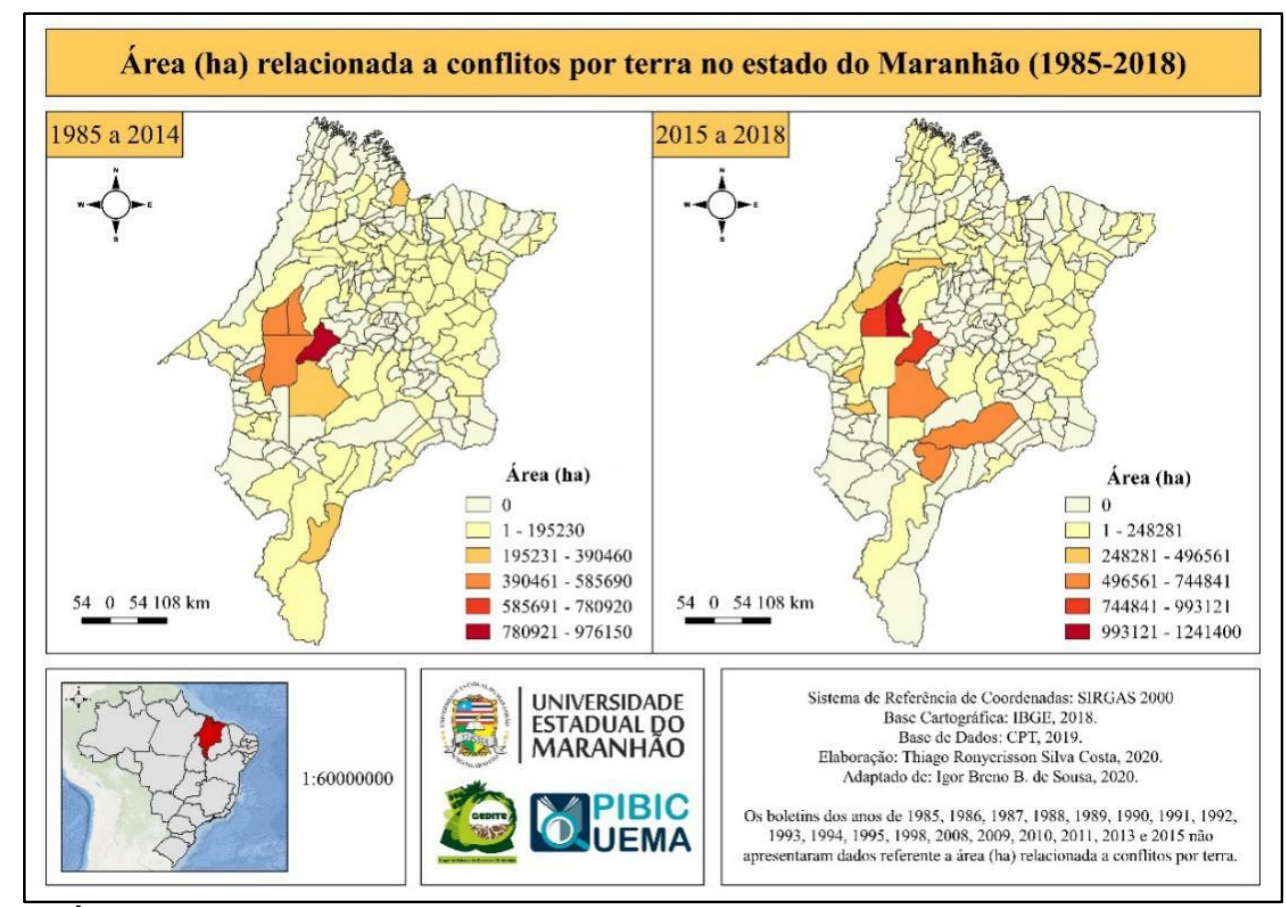

Figura 6. Área (ha) relacionada a conflitos por terra no estado do Maranhão (1985-2018).

Elaboração: Os autores.

No Maranhão, observa-se que grande parte dos registros de áreas em conflitos encontram-se em municípios com grandes extensões territoriais, como Amarante do Maranhão, Bom Jesus das Selvas, Grajaú e Arame entre 1985 e 2014 e a adição de Bom Jardim e São Raimundo das Mangabeiras, a partir de 2015. Nota-se que estes municípios, apesar de não disporem de muitos conflitos no estado, envolvem muitas famílias, fator ligado diretamente a extensão da área.

Assim, observa-se que no campo a conflitualidade territorial se dá, em grande parte, na reprodução contínua "da histórica concentração de terras" e das "enormes barreiras encontradas pelos grupos sociais que reivindicam seus direitos territoriais para reverter esta permanência histórica" (GERMANI, 2010, p. 270). 
No Maranhão, entre os anos de 2015 a 2018 o número de ocorrências de conflitos por terra, integra os municípios de Codó, Alcântara, Matinha, Itapecuru-Mirim, São Luís e São Benedito do Rio Preto, ressalta-se que nestes municípios o padrão do número de conflitos nem sempre acompanha o do número de famílias envolvidas diretamente nesses conflitos. Enfatiza-se que, o número de famílias envolvidas nos conflitos pode ser maior, pois segundo a CPT (2018) em determinadas situações não registra-se ocorrência a polícia e/ou a CPT, em alguns casos, a própria CPT cataloga os dados que constam junto aos números oficiais.

Em munícipios como Balsas e Alcântara, o número de famílias envolvidas diretamente nos conflitos é pequeno se comparado a São Luís, Matinha e Itapecuru-Mirim. Alguns municípios apresentam famílias ligadas a conflitos sem registros de conflitos, como; Buriti Bravo e Passagem Franca, ambos localizados a Sudeste do estado e Marajá do Sena, localizado no Centro do estado. Estes processos estão ligados diretamente a forma como o registro é feito, conforme mencionado anteriormente.

A ocupação é a principal estratégia de luta pela terra realizada pelos movimentos da estrutura social no estado, a partir disso desencadeiam-se na maioria das vezes os conflitos. Os boletins de conflitos agrários da CPT, mostram que entre 2015 e 2018 foram registradas ocupações de terra realizadas por mais de vinte diferentes movimentos no Maranhão. As áreas ocupadas são principalmente latifúndios improdutivos, terras devolutas e imóveis rurais onde leis ambientais e trabalhistas foram desrespeitadas. De modo geral, as propriedades ocupadas são aquelas que apresentam indicativos de descumprimento da função social da terra, definida no artigo 186 da Constituição Federal de 1988. A tabela 1 ajuda a traçar um panorama dos indicadores desses conflitos, vejamos:

Tabela 1. Lista dos 10 municípios com o maior registro de ocorrências de conflitos por terra no estado do Maranhão (1985-2018)

\begin{tabular}{clcc}
\hline Ordem & \multicolumn{1}{c}{ Município } & Média de ocorrências & $\begin{array}{c}\text { Participação no total geral } \\
\text { do estado }\end{array}$ \\
\hline 1 & Codó & 4 & $5 \%$ \\
2 & Urbano Santos & 3 & $3 \%$ \\
3 & Alcântara & 3 & $3 \%$ \\
4 & Parnarama & 2 & $3 \%$ \\
5 & Itapecuru Mirim & 2 & $3 \%$ \\
6 & São Luís & 2 & $3 \%$ \\
7 & Balsas & 2 & $2 \%$ \\
8 & Santa Quitéria do Maranhão & 2 & $2 \%$ \\
9 & Alto Alegre do Maranhão & 2 & $2 \%$ \\
10 & Arari & 2 & $2 \%$ \\
\hline Total & Maranhão & 84 & - \\
\hline
\end{tabular}

Fonte: CPT, (2019).

Os dez municípios com os maiores registros de conflitos por terra no Maranhão são responsáveis por $27,35 \%$ do total geral de conflitos, ou seja, $4,60 \%$ do total de munícipios são responsáveis por mais de um quarto em participação no número de conflitos. Esse processo está ligado a fatores como expulsão de famílias tradicionais de suas terras, instalação de cadeias produtivas ligadas ao capital e a infraestrtutura 
para dinamizar a sua atuação, a exemplo de rodovias e ferrovias, ao Estado ao conceder incentivos fiscais e/ou de alguns de seus agentes participes neste processo, avanço da pecuária extensiva e do desmatamento, crescimento do processo de grilagem e das ameaças ordenadas à estrutura social ali instalada.

Ressalta-se que esses municípios apresentam características heterogêneas entre si quanto aos conflitos por terra e suas variáveis. Entretanto, a maioria dos processos conflitivos estão relacionados à instalação de atividades produtivas ligadas aos interesses da estrutura do capital que, por sua vez, conta quase sempre com o apoio do Estado, consoante aos interesses mútuos entre esses, notório ao processo de acúmulo de poder por parte do "grande latifúndio" e a dissonância de poder entre as estruturas social e do capital.

Em suma, os conflitos por terra apresentam uma dinâmica heterogênea quanto a espacialização, com presença em todas as regiões do estado. Por traz desses números, existem famílias compostas apenas por mulheres e crianças que lutam diariamente para garantir seu sustento e renda. Aqui, cabe destacar o papel do processo da política fundiária no Brasil, na qual Fernandes et al (2012) afirmam que o Brasil preserva uma das mais concentradas estruturas fundiárias no mundo, fato que pesa diretamente no número de famílias envolvidas nos processos de conflitos por terra.

\section{CONSIDERAÇÕES FINAIS}

O Maranhão chega ao século XXI com elevados índices de desigualdades sociais impulsionadas, em sua maioria pela entrada da estrutura do capital, assegurado essencialmente por ambos os poderes do Estado em seu quadro histórico. No contexto das novas territorialidades difundidas pela instauração da estrutura excludente do capital, que geralmente atendem os interesses de uma minoria, iniciamse os processos que desencadeiam conflitos e suas conflitualidades, as quais acarretam alterações sociais, econômicas, culturais e ambientais no campo, recaindo sobre toda a sociedade maranhense.

Diante deste agravo, percebe-se que a realização da política fundiária faz-se necessária, pois beneficia uma grande quantidade de famílias de base camponesa, tirando-as da situação de extrema pobreza, conferindo o papel democrático do direito à terra. Assim, entende-se que a política fundiária assume um projeto contra a estrutura excludente do capital, propondo benefícios, na medida em que ela compreenda as demandas da estrutura social que vive no/e do campo. Na contramão desta perspectiva, há a permanência de um quadro contraditório no que tange a questão fundiária no Brasil e, principalmente, no Maranhão, visto que encontramos no estado uma grande quantidade de latifúndios improdutivos e excludentes que resultam em grandes e violentos conflitos agrários.

Se por um lado, o processo de territorialização acirra mais ainda o processo de desigualdades, por outro, abre também possibilidades para um processo mais intenso de lutas e com isso as conflitualidades. Por mais que haja uma crise na estrutura social do campo, os processos de luta precisam estar articulados não apenas no sentido de 
manutenção e garantia das conquistas dos direitos sociais adquiridos por meio da luta de uma sociedade que vive no/e do campo, mas também para avançar rumo à sua emancipação e garantir o acesso à terra.

A legitimidade na mediação de conflitos deve levar em consideração a estrutura social, que deve ter seus direitos reconhecidos perante os instrumentos constitucionais. A proteção as pessoas que sofrem violência, intimidação e ameaças deve ser garantido. O combate à corrupção e ilegalidades, vivenciado nos órgãos institucionais e de Estado relacionados a questão agrária, além de fornecer subsídios de forma assertiva à estrutura social. Portanto, é necessário fomentar a articulação de movimentos dentro da estrutura social para estruturar uma política fundiária efetiva, que pode e deve ser parte de uma estratégia política destinada a combater ao mesmo tempo à desigualdade, à miséria e ao desemprego e contribuir para superação do atual modelo de concentração fundiária, aplacar o processo de conflitos e conflitualidades e construir uma sociedade onde a vida tenha mais importância que os interesses do capital.

Por fim, em todos os casos analisados, a estrutura social, apesar das constantes pressões infligidas, segue na luta, seja pelo acesso à terra ou à sua permanência nestas.

\section{REFERÊNCIAS}

ALMEIDA, J. G; SODRÉ, R. B; MATTOS JUNIOR, J. S. de. O MATOPIBA nas chapadas maranhenses: impactos da expansão do agronegócio na microrregião de Chapadinha. Rev. NERA, Presidente Prudente, v. 22, n. 47, p. 248-271, 2019.

ANTUNES, R. O colapso do governo Dilma e do PT no Brasil. Herramienta, Buenos Aires, v. 57, 2015.

ARCANGELI, A. O mito da terra: uma análise da colonização da Pré-Amazônia maranhense. São Luís: UFMA/PPPG/EDUFMA, 1987.

ASSELIN, V. Grilagem: corrupção e violência em terras do Carajás. Imperatriz: Ética, 2009.

COELHO, F. Reforma Agrária no governo FHC: perfil, tensões, número de famílias assentadas e áreas obtidas. Rev. Diálogos, v. 20, n. 2, p. 179-192, 2016. Disponível em: < http://periodicos.uem.br/ojs/index.php/Dialogos/article/view/34575 >. Acesso em: 18 jan. 2020.

COMISSÃO PASTORAL DA TERRA. Conflitos no Campo - Brasil. Goiânia, 1988. Disponível em: < https://www.cptnacional.org.br/publicacoes-2/conflitos-no-campobrasil >. Acesso em: 20 dez. 2019. 
COMISSÃO PASTORAL DA TERRA. Conflitos no Campo - Brasil. Goiânia, 2012. Disponível em: < https://www.cptnacional.org.br/publicacoes-2/conflitos-no-campobrasil >. Acesso em: $20 \mathrm{dez} .2019$.

COMISSÃO PASTORAL DA TERRA. Conflitos no Campo - Brasil. Goiânia, 2015. Disponível em: < https://www.cptnacional.org.br/publicacoes-2/conflitos-no-campobrasil >. Acesso em: 20 dez. 2019.

COMISSÃO PASTORAL DA TERRA. Conflitos no Campo - Brasil. Goiânia, 2018. Disponível em: < https://www.cptnacional.org.br/publicacoes-2/conflitos-no-campobrasil >. Acesso em: 20 dez. 2019.

FERNANDES, B. M. Movimentos socioterritoriais e movimentos socioespaciais: contribuição teórica para uma leitura geográfica dos movimentos sociais. Rev. NERA, ano 8, n. 6, jan./jun. 2005. Disponível em: < https://revista.fct.unesp.br/index.php/nera/article/view/1460 >. Acesso em: $20 \mathrm{dez}$. 2019.

FERNANDES, B. M. Reforma Agrária no governo Lula: a esperança. FCT/UNESP. Set. 2003. Disponível em: < http://www2.fct.unesp.br/nera/publicacoes/LULA RA.pdf $>$ Acesso em: 20 abr. 2020.

FERNANDES, B. M; WELCH, C. A; GONÇALVES, E. C. Políticas Fundiárias no Brasil: uma análise geo-histórica da governança da terra no Brasil. Land Governance in Brazil. Framing the Debate Series, n. 2. ILC, Roma, 2012. Disponível em: < https://revista.fct.unesp.br/index.php/nera/article/view/2751. >. Acesso em: $20 \mathrm{dez}$. 2019.

GERMANI, G. I. Questão agrária e movimentos sociais: a territorialização da luta pela terra na Bahia. In: COELHO NETO, A. S.; SANTOS, E. M. C.; SILVA, O. A. (Geo)grafias dos movimentos sociais. Feira de Santana, BA: UEFS, 2010. 392p. 269304.

GIRARDI, E. P; FERNANDES, B. M. A luta pela terra e a política de assentamentos rurais no Brasil: A reforma agrária conservadora. Rev. Agrária, São Paulo, n 8, p. 73$98,2008$.

Instituto Brasileiro de Geografia e Estatística - IBGE. Portal IBGE Cidades. Disponível em: < https://cidades.ibge.gov.br/brasil/ma >. Acesso em: 20 jan. 2020.

Instituto Brasileiro de Geografia e Estatística - IBGE. SIS - Síntese de Indicadores Sociais. Disponível: < https://www.ibge.gov.br/estatisticas/sociais/protecaosocial/9221-sintese-de-indicadores-sociais.html?edicao $=29143 \& \mathrm{t}=$ sobre $>$. Acesso em: 25 jan. 2020. 
MARX, K. O capital: crítica da economia política. 25 ed. Rio de Janeiro: Civilização Brasileira, 2008.

OLIVEIRA, A. U. de. A longa marcha do campesinato brasileiro: movimentos sociais, conflitos e Reforma Agrária. Rev. Estudos Avançados, São Paulo, v. 15, n. 43, p. 185206, dez. 2001. Disponível em: < https://www.revistas.usp.br/eav/article/view/9831 >. Acesso em: 20 abr. 2020.

OLIVEIRA, A. U. de. Reforma Agrária no Governo Lula: a esperança. FCT/UNESP. Set. 2003. Disponível em: < http://www2.fct.unesp.br/nera/publicacoes/LULA RA.pdf >. Acesso em: 20 abr. 2020. XII COLÓQUIO DE GEOCRÍTICA. UNIVERSIDAD NACIONAL DE COLOMBIA. A mundialização da agricultura brasileira. Bogotá, 7 a 11 mai. 2012.

SODRÉ, R. B. O Maranhão Agrário: dinâmicas e conflitos territoriais. 2017. Dissertação (Mestrado em Geografia) - Centro de Educação, Ciências Exatas e Naturais, Universidade Estadual do Maranhão, São Luís, 2017. 211 f.

SODRÉ, R; MATTOS, J. O emaranhado dos conflitos de terra no campo maranhense. Rev. de Geografia e Ordenamento do Território (GOT), n. 10, p. 345-354, 2016.

THOMAZ JUNIOR, A. "Jogo" de cena e poder de classe no Brasil do século XXI. A contrarreforma agrária no Governo Lula. Presidente Prudente (SP), Rev. Pegada, n.4, v.1, 2003, p. 05-17. Disponível em: < https://revista.fct.unesp.br/index.php/pegada/article/view/819 >. Acesso em: 20 abr. 2020. 